\section{Crisis foments as} unstable lake builds in the Himalayas

\section{K. S. Jayaraman, New Delhi}

Landslides on the India-China border have created a lake holding millions of cubic metres of water. Scientists and engineers in the region are puzzling over how to avoid a catastrophic collapse of the lake wall, but Indian researchers say their plans have been hampered by China's refusal to allow them to visit the site.

The Chinese government warned on

11 August that landslides had blocked the Pare Chu river in Tibet, creating a lake about 40 metres deep and holding 60 million cubic metres of water. China said it was evacuating people downstream and advised India to do the same. The river enters India about 35 kilometres from the lake and, as the Sutlej, continues past several towns in Himachal Pradesh.

According to Muthaia Perumal, a hydrologist at the Indian Institute of Technology (IIT) in Roorkee, the water will rush into a narrow gorge should the lake wall break. "It will not be like floods in the plains where water can spread out," he says."We expect a huge wall of water moving in bulk without its height diminishing."

Creating tunnels in the lake wall could have provided an exit for the accumulating water had measures been taken when the landslides occurred in early July, says Manoj Datta, a civil engineer at the IIT in Delhi. "Now the dam is overflowing it is too risky to try anything," he adds. The Indian government has evacuated 50,000 people from the danger zone.

Indian researchers regret that a joint strategy was not put in place early on, but the Indian government said on 13 August that a request to China for permission to send scientists and engineers to the site had been rebuffed. The Chinese government says the site is difficult to reach and is briefing Indian authorities on progress made by its own team at the lake. Chinese hydrologists working on the lake could not be reached for comment.

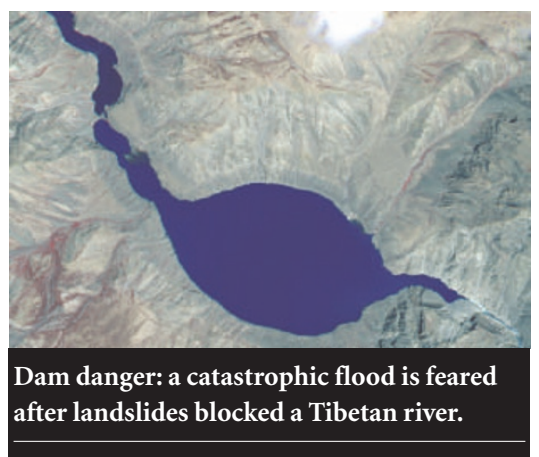

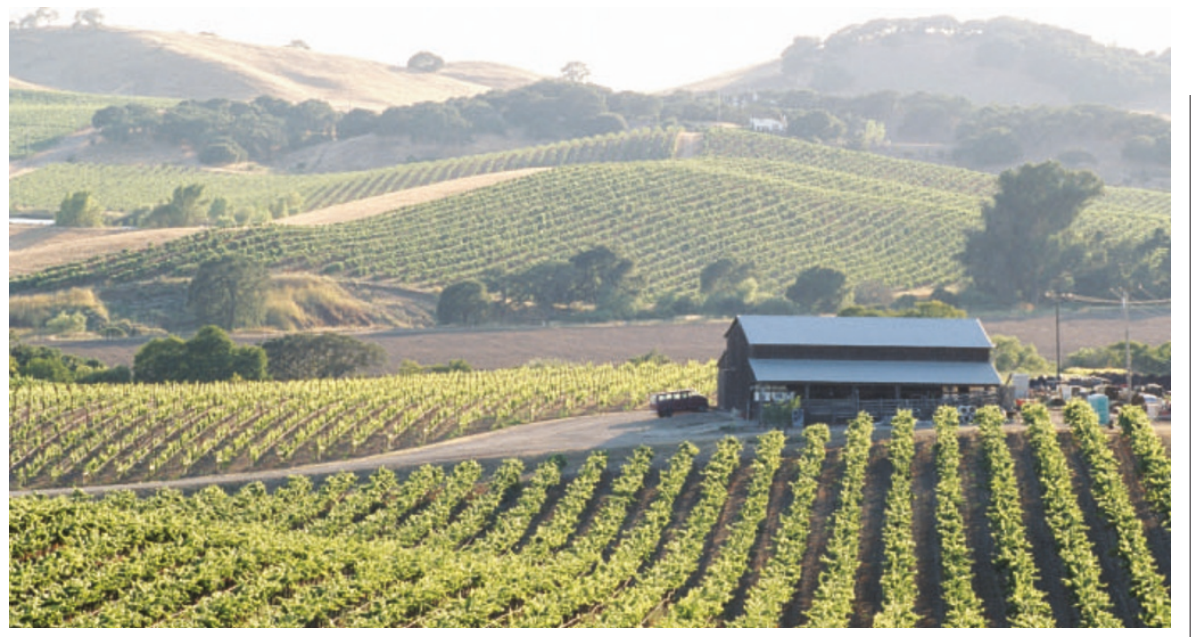

Green remembered hills: the wine of the Napa valley could lose its edge if emissions are not reduced.

\title{
Climate modellers go local to target California's politicians
}

\section{Emma Marris}

A "pioneering" example of a new breed of climate model, designed to plug the gap between academic research and political decision making, has been published.

The analysis of California's climate by Katharine Hayhoe and colleagues outlines how conditions in the state will change under two alternative scenarios: one models the state's future under aggressive policies to reduce carbon dioxide emissions; the other predicts its fate without them. The result is an analysis of the implications for heatrelated human mortality, the water cycle and agriculture. It is designed to influence the state's policy-makers.

"Other researchers looked at just one scenario, which is kind of fatalistic," says Hayhoe, who is based at the University of Illinois at Urbana-Champaign. "This way you have a choice."

Rajendra Pachauri, chairman of the Intergovernmental Panel on Climate Change (IPCC), has flagged up such regional studies as a vital part of the panel's next assessment (see Nature 417, 106; 2002). In this case, the project was suggested to Hayhoe by the Washington-based Union of Concerned Scientists (UCS), which fears that the findings of climate-change science are not being disseminated in a useful form.

The study, which is published in print on 16 August (K. Hayhoe et al. Proc. Natl Acad. Sci. USA doi:10.1073/pnas.0404500101), uses data from two global climate models, along with local weather histories. In the highemissions scenario, there will be six to eight times more heat waves and five to seven times more heat-related deaths in 2100 than there are now. Alpine forests will practically disappear, snow packs will shrink and the vineyards will move from producing gourmet wine to plonk.

"What we did is a model for a regional assessment," says Hayhoe, who adds that the team chose California because the state is both tough and potentially responsive. "It has a lot of different climate zones, so it is challenging. Also, California is a leader in terms of reduction of emissions. It might actually use our findings."

Hayhoe hopes her forecasts will be politically effective, but says she wants the science to be unbiased and to be perceived as being so. She adds that her team used low estimates for emissions and their effect on the climate: "We tried to err on the conservative side." She also says that after the initial suggestion, the UCS stepped aside, although two authors do list the UCS as an affiliation. State officials declined requests to comment on the paper.

The study is "pioneering", according to Warren Washington, a climate researcher at the US National Center for Atmospheric Research in Boulder, Colorado, who provided tailored data from the centre's global climate model. He predicts that the format will be popular. "This type of paper and analysis will be repeated for many regions around the world," says Washington.

Regional assessments are becoming more feasible as computing power improves, adds David Viner, of the IPCC's Data Distribution Centre at the University of East Anglia in Norwich, UK. The regional models, although huge, can now be done on off-the-shelf computers. "I've got a G5 Power Mac on my desk, which has the capability of a supercomputer from five or ten years ago," says Viner. "There are lots of people doing this now."

He adds that moving the data around is probably more problematic than producing it. Global models, which can require up to 5,000 gigabytes of memory, are starting to become publicly available on the Internet. However, they do not yet provide the detail needed for a rigorous local model. 